\title{
EFFECT OF ATRIAL FIBRILLATION ON CARDIAC OUTPUT
}

\author{
BY \\ P. B. HALMOS* AND G. C. PATTERSON
}

From the Royal Victoria Hospital, Belfast

Received October 12, 1964

The introduction by Lown, Amarasingham, and Neuman (1962) of a safe, simple, and effective method of converting atrial fibrillation to sinus rhythm has increased the interest in the effects of this arrhythmia on the circulation. Previous reports indicate scant agreement regarding the effects of atrial fibrillation on the cardiac output. Studies on groups of patients with and without atrial fibrillation have been associated with the difficulty of obtaining strictly comparable groups. Cardiac output studied on the same patients before and after drug conversions to sinus rhythm have been complicated by the effect on output of the drugs employed.

The present study was undertaken to determine the changes, if any, on cardiac output when atrial fibrillation was removed by direct current conversion.

\section{SubJeCtS AND Methods}

Studies were carried out on 30 patients who had had atrial fibrillation for periods varying from 3 weeks to 10 years. Data on these patients are given in Tables I and II. Of the 30, 23 had rheumatic heart disease, 3 had idiopathic atrial fibrillation, 2 ischæmic heart disease, one controlled thyrotoxicosis, and in one atrial fibrillation persisted following pericardectomy for constrictive pericarditis. Of the 23 patients with rheumatic heart disease, 20 had had mitral valvotomy from 3 weeks to several years before conversion. All the patients were on maintenance digitalis. None showed evidence of cardiac failure.

The patients were in hospital for at least 24 hours before output studies were made. Cardiac output was measured in the early morning by the dye dilution technique.(Bruce and Shillingford, 1962). The procedure was explained to the patient the previous evening. The heart rate was recorded at the time of each output estimation.

An attempt was made to establish sinus rhythm within a few days of the cardiac output estimation. Sinus rhythm was achieved in 20 patients. When sinus rhythm was established digitalis therapy was discontinued. After conversion 8 patients received quinidine sulphate $1.2 \mathrm{~g}$. daily, and 6 received potassium chloride $8 \mathrm{~g}$. daily given in divided doses. The remaining 6 received no drug therapy. Digitalis therapy was continued in the group of 10 patients in whom sinus rhythm was not achieved. Cardiac output was measured again approximately one week after conversion or attempted conversion.

In 6 patients in whom sinus rhythm had been established a third estimation of cardiac output was made 6-10 weeks after conversion. At this time atrial fibrillation had appeared in 3, while in the others sinus rhythm had been maintained.

\section{RESULTS}

Figure 1A shows the results of output studies in 20 patients before and after conversion to sinus rhythm. In 18 patients the output was increased and in 2 it remained unchanged. The average

* In receipt of a Royal Victoria Hospital Research Fellowship. 
TABLE I

Details of 20 Patients in whom Conversion to Sinus Rhythm was Successful

\begin{tabular}{|c|c|c|c|c|c|c|c|c|c|c|}
\hline \multirow{2}{*}{\multicolumn{3}{|c|}{$\begin{array}{l}\text { Patient, } \\
\text { age (yr.), and } \\
\text { sex }\end{array}$}} & \multirow{2}{*}{$\begin{array}{c}\text { Duration } \\
\text { of } \\
\text { A.F. }\end{array}$} & \multicolumn{3}{|c|}{ Before conversion } & \multicolumn{4}{|c|}{ After conversion } \\
\hline & & & & H.R. & $\begin{array}{l}\text { C.O. } \\
\text { (1./min.) }\end{array}$ & $\begin{array}{l}\text { Stroke vol. } \\
\text { (ml.) }\end{array}$ & H.R. & $\begin{array}{c}\text { C.O. } \\
\text { (l./min.) }\end{array}$ & $\begin{array}{l}\text { Stroke vol. } \\
\text { (ml.) }\end{array}$ & M.T. \\
\hline $\begin{array}{l}\text { R.S. } \\
\text { M.F. } \\
\text { R.T. } \\
\text { J.T. } \\
\text { H.T. } \\
\text { M.M. } \\
\text { S.R. } \\
\text { K.O. } \\
\text { O.F. } \\
\text { A.R. } \\
\text { J.S. } \\
\text { M.G. } \\
\text { W.G. } \\
\text { S.L. } \\
\text { A.B. } \\
\text { W.M. } \\
\text { S.P. } \\
\text { J.C. } \\
\text { M.K. } \\
\text { W.C. }\end{array}$ & $\begin{array}{l}52 \\
49 \\
32 \\
31 \\
65 \\
43 \\
40 \\
66 \\
50 \\
41 \\
58 \\
53 \\
52 \\
52 \\
37 \\
42 \\
61 \\
56 \\
39 \\
64\end{array}$ & $\begin{array}{l}\mathrm{M} \\
\mathrm{F} \\
\mathrm{M} \\
\mathrm{F} \\
\mathrm{M} \\
\mathrm{F} \\
\mathrm{M} \\
\mathrm{F} \\
\mathrm{M} \\
\mathrm{M} \\
\mathrm{F} \\
\mathrm{F} \\
\mathrm{M} \\
\mathrm{M} \\
\mathrm{M} \\
\mathrm{M} \\
\mathrm{F} \\
\mathrm{M} \\
\mathrm{F} \\
\mathrm{M}\end{array}$ & $\begin{array}{l}3 \mathrm{wk} . \\
6 \mathrm{mth} . \\
3 \mathrm{yr} . \\
3 \mathrm{yr} . \\
2 \mathrm{yr} . \\
3 \mathrm{yr} . \\
5 \mathrm{yr} . \\
2 \mathrm{mth} . \\
1 \mathrm{mth} . \\
18 \mathrm{mth} . \\
16 \mathrm{yr} . \\
6 \mathrm{yr} . \\
1 \mathrm{yr} . \\
1 \mathrm{yr} . \\
3 \mathrm{mth} . \\
2 \mathrm{mth} . \\
1 \mathrm{mth} . \\
3 \mathrm{yr} . \\
18 \mathrm{mth} . \\
10 \mathrm{yr} .\end{array}$ & $\begin{array}{l}80 \\
90 \\
75 \\
80 \\
72 \\
80 \\
86 \\
68 \\
80 \\
86 \\
88 \\
78 \\
64 \\
70 \\
80 \\
76 \\
72 \\
76 \\
86 \\
58\end{array}$ & $\begin{array}{l}3 \cdot 6 \\
4 \cdot 1 \\
4 \cdot 5 \\
4.9 \\
3 \cdot 5 \\
3 \cdot 7 \\
6 \cdot 0 \\
3 \cdot 4 \\
3 \cdot 6 \\
4 \cdot 7 \\
4 \cdot 7 \\
2 \cdot 6 \\
5 \cdot 9 \\
4 \cdot 0 \\
4.4 \\
4.0 \\
3.5 \\
3.4 \\
3.7 \\
2.9\end{array}$ & $\begin{array}{l}45 \\
46 \\
60 \\
61 \\
49 \\
46 \\
79 \\
50 \\
45 \\
55 \\
53 \\
33 \\
92 \\
57 \\
55 \\
53 \\
48 \\
45 \\
42 \\
50\end{array}$ & $\begin{array}{l}85 \\
80 \\
90 \\
66 \\
70 \\
76 \\
80 \\
70 \\
78 \\
80 \\
82 \\
74 \\
70 \\
70 \\
68 \\
72 \\
66 \\
70 \\
80 \\
65\end{array}$ & $\begin{array}{r}11 \cdot 2 \\
6 \cdot 7 \\
9 \cdot 5 \\
4 \cdot 8 \\
6 \cdot 2 \\
5 \cdot 3 \\
5 \cdot 8 \\
5 \cdot 3 \\
5 \cdot 7 \\
6 \cdot 7 \\
6 \cdot 3 \\
4 \cdot 7 \\
7 \cdot 2 \\
5 \cdot 5 \\
6 \cdot 0 \\
5 \cdot 6 \\
5 \cdot 3 \\
5 \cdot 4 \\
4 \cdot 3 \\
3 \cdot 9\end{array}$ & $\begin{array}{r}85 \\
84 \\
106 \\
73 \\
88 \\
69 \\
72 \\
76 \\
73 \\
84 \\
77 \\
64 \\
103 \\
78 \\
88 \\
78 \\
80 \\
77 \\
54 \\
60\end{array}$ & $\begin{array}{l}\bar{Q} \\
\mathrm{Q} \\
\mathrm{Q} \\
\mathrm{Q} \\
\mathrm{Q} \\
\mathrm{K} \\
\mathrm{Q} \\
\mathrm{Q} \\
\mathrm{K} \\
\mathrm{Q} \\
\mathrm{K} \\
\mathrm{K} \\
\mathrm{K} \\
\mathrm{K} \\
\mathbf{Z} \\
=\end{array}$ \\
\hline
\end{tabular}

C.O., cardiac output; H.R., heart rate; A.F., atrial fibrillation; M.T., maintenance drug therapy; Q, quinidine 1·2 g. daily; $\mathbf{K}$, potassium chloride $8 \mathrm{~g}$. daily.

TABLE II

Details of 10 Patients in whom Conversion to Sinus Rhythm was UnSUCCessful

\begin{tabular}{|c|c|c|c|c|c|c|c|c|c|c|}
\hline \multirow{2}{*}{\multicolumn{3}{|c|}{$\begin{array}{l}\text { Patient, } \\
\text { age (yr.), and } \\
\text { sex }\end{array}$}} & \multirow{2}{*}{$\begin{array}{l}\text { Duration } \\
\text { of } \\
\text { A.F. (yr.) }\end{array}$} & \multicolumn{3}{|c|}{ Before conversion } & \multicolumn{4}{|c|}{ After attempted conversion } \\
\hline & & & & H.R. & $\begin{array}{c}\text { C.O. } \\
\text { (1./min.) }\end{array}$ & $\begin{array}{l}\text { Stroke vol. } \\
\text { (ml.) }\end{array}$ & H.R. & $\begin{array}{l}\text { C.O. } \\
\text { (1./min.) }\end{array}$ & $\begin{array}{l}\text { Stroke vol. } \\
\text { (ml.) }\end{array}$ & M.T. \\
\hline $\begin{array}{l}\text { R.P. } \\
\text { M.H. } \\
\text { R.C. } \\
\text { M.F. } \\
\text { N.D. } \\
\text { S.W. } \\
\text { G.S. } \\
\text { S.D. } \\
\text { T.W. } \\
\text { S.O. }\end{array}$ & $\begin{array}{l}50 \\
42 \\
32 \\
47 \\
53 \\
40 \\
56 \\
43 \\
66 \\
54\end{array}$ & $\begin{array}{l}\mathrm{F} \\
\mathrm{F} \\
\mathrm{F} \\
\mathrm{F} \\
\mathrm{F} \\
\mathrm{M} \\
\mathrm{M} \\
\mathrm{F} \\
\mathrm{M} \\
\mathrm{M}\end{array}$ & $\begin{array}{r}9 \\
6 \\
1 \\
9 \\
4 \\
6 \\
6 \\
6 \\
2 \\
10\end{array}$ & $\begin{array}{l}86 \\
70 \\
74 \\
74 \\
64 \\
68 \\
82 \\
74 \\
70 \\
80\end{array}$ & $\begin{array}{l}4 \cdot 7 \\
4 \cdot 5 \\
4 \cdot 5 \\
3 \cdot 9 \\
4 \cdot 9 \\
4 \cdot 2 \\
3 \cdot 7 \\
4 \cdot 1 \\
4 \cdot 0 \\
3 \cdot 4\end{array}$ & $\begin{array}{l}54 \\
64 \\
61 \\
53 \\
77 \\
62 \\
45 \\
55 \\
57 \\
42\end{array}$ & $\begin{array}{l}74 \\
78 \\
68 \\
70 \\
68 \\
72 \\
78 \\
72 \\
68 \\
75\end{array}$ & $\begin{array}{l}5 \cdot 2 \\
4 \cdot 6 \\
4 \cdot 4 \\
4 \cdot 1 \\
4 \cdot 7 \\
4 \cdot 5 \\
3.9 \\
3 \cdot 8 \\
3.9 \\
3.9\end{array}$ & $\begin{array}{l}70 \\
59 \\
65 \\
58 \\
69 \\
62 \\
50 \\
53 \\
57 \\
52\end{array}$ & $\begin{array}{l}\text { D } \\
\text { D } \\
\text { D } \\
\text { D } \\
\text { D } \\
\text { D } \\
\text { D } \\
\text { D } \\
\text { D } \\
\text { D }\end{array}$ \\
\hline
\end{tabular}

C.O., cardiac output; H.R., heart rate; M.T., maintenance drug therapy; D, digoxin $0.25 \mathrm{mg}$. twice daily.

increase in cardiac output following conversion was 53 per cent of the pre-conversion value. In one (No. 1) the output increased from 3.6 to $11.51 . / \mathrm{min}$.: this patient had a repeat output measurement 10 weeks later and a value of $9.5 \mathrm{l}$. was obtained. Clinical investigation revealed no cause for the high cardiac output. Thyroid hyperactivity was excluded.

Figure 1B shows the change in stroke volume following the establishment of sinus rhythm. In 19 of the 20 patients there was an increase in stroke volume. In one there was little change from the 

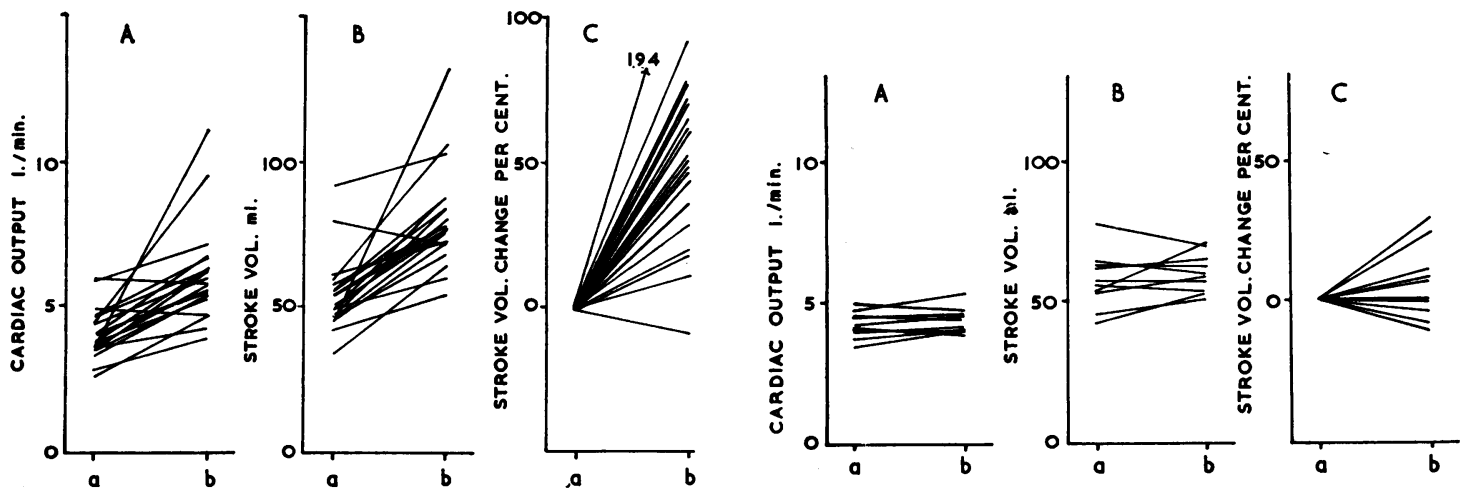

FIG. 1.-(A) The cardiac output before (a) and after (b) successful conversion from atrial fibrillation to sinus rhythm. (B) The stroke volume. (C) The change in stroke volume expressed as a percentage of the resting value.

Fig. 2.-(A) The cardiac output before (a) and after (b) failure to convert atrial fibrillation to sinus rhythm. (B) The stroke volume. (C) The change in stroke volume expressed as a percentage of the resting value.

pre-conversion figure. In Fig. $1 \mathrm{C}$ the increase in stroke volume has been calculated as a percentage of the resting stroke volume.

Of the 30 patients with atrial fibrillation who were given a direct current shock in an attempt to abolish the arrhythmia, atrial fibrillation persisted in 10. Fig. 2A shows the cardiac output measurements in these patients obtained before and after attempted conversion. In all of them there was little change in cardiac output. Fig. 2B shows the stroke volume and Fig. $2 \mathrm{C}$ the change in stroke volume expressed as a percentage of the resting stroke volume. There is little change in stroke volume in this group.

Three patients in whom sinus rhythm had been established but in whom atrial fibrillation had reappeared had a further measurement of cardiac output made (Fig. 3). The reappearance of atrial fibrillation was accompanied by a fall in cardiac output and stroke volume to near the pre-conversion level. In 3 patients in whom sinus rhythm had been maintained the cardiac output and stroke volume remained near the level obtained one week after conversion to sinus rhythm. The results are shown in Table III.

Of the 20 patients in whom sinus rhythm was achieved, 8 were given quinidine sulphate and 6 potassium chloride as maintenance therapy. The remaining 6 received no drug therapy. Fig. 4 shows the cardiac output and percentage increase in stroke volume occurring in these three groups.

TABLE III

Details of 6 Patients Studied a Third Time, 6 to 8 Weers after Conversion; 3 Patients had Reverted to Atrial FIBRILlation

\begin{tabular}{|c|c|c|c|c|c|c|c|c|c|c|}
\hline \multirow{2}{*}{ Patients } & \multicolumn{3}{|c|}{ Before conversion } & \multicolumn{3}{|c|}{ After conversion } & \multicolumn{4}{|c|}{ 6-8 weeks later } \\
\hline & H.R. & $\begin{array}{l}\text { C.O. } \\
\text { (1./min.) }\end{array}$ & $\begin{array}{c}\text { Stroke } \\
\text { vol. (ml.) }\end{array}$ & H.R. & $\begin{array}{l}\text { C.O. } \\
\text { (1./min.) }\end{array}$ & $\begin{array}{c}\text { Stroke } \\
\text { vol. (ml.) }\end{array}$ & H.R. & $\begin{array}{l}\text { C.O. } \\
\text { (1./min.) }\end{array}$ & $\begin{array}{c}\text { Stroke } \\
\text { vol. (ml.) }\end{array}$ & Rhythm \\
\hline $\begin{array}{l}\text { M.G. } \\
\text { I.S. } \\
\text { H.T. } \\
\text { A.R. } \\
\text { R.T. } \\
\text { J.C. }\end{array}$ & $\begin{array}{l}78 \\
88 \\
72 \\
86 \\
75 \\
76\end{array}$ & $\begin{array}{l}2 \cdot 6 \\
4 \cdot 7 \\
3 \cdot 5 \\
4 \cdot 7 \\
4 \cdot 5 \\
3 \cdot 4\end{array}$ & $\begin{array}{l}33 \\
53 \\
49 \\
55 \\
60 \\
45\end{array}$ & $\begin{array}{l}74 \\
82 \\
70 \\
80 \\
90 \\
70\end{array}$ & $\begin{array}{l}4 \cdot 7 \\
6 \cdot 3 \\
6 \cdot 2 \\
6 \cdot 7 \\
9 \cdot 5 \\
5 \cdot 4\end{array}$ & $\begin{array}{r}64 \\
77 \\
88 \\
84 \\
106 \\
77\end{array}$ & $\begin{array}{l}66 \\
70 \\
80 \\
66 \\
86 \\
68\end{array}$ & $\begin{array}{l}3 \cdot 3 \\
3 \cdot 8 \\
5 \cdot 9 \\
4 \cdot 3 \\
8 \cdot 0 \\
5 \cdot 0\end{array}$ & $\begin{array}{l}50 \\
54 \\
74 \\
65 \\
93 \\
73\end{array}$ & $\begin{array}{l}\text { A.F. } \\
\text { A.F. } \\
\text { S.R. } \\
\text { A.F. } \\
\text { S.R. } \\
\text { S.R. }\end{array}$ \\
\hline
\end{tabular}

C.O., cardiac output; H.R., heart rate; A.F., atrial fibrillation; S.R., sinus rhythm. 

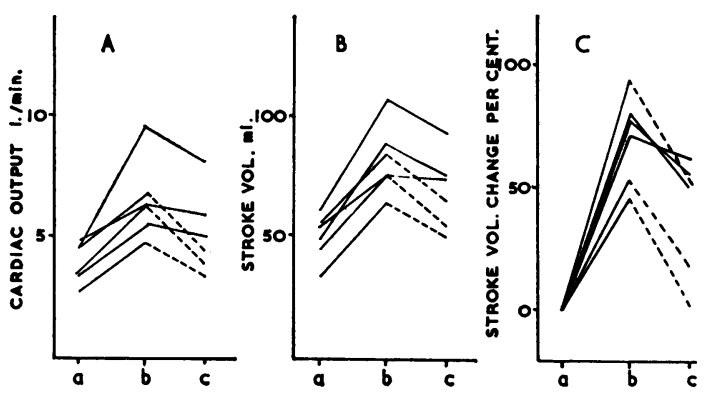

FIG. 3.-(A) The cardiac output before (a), after (b), and some time after (c) conversion of atrial fibrillation to sinus rhythm. The dotted line indicates reversion to atrial fibrillation in 3 patients. (B) The stroke volume. (C) The change in stroke volume expressed as a percentage of the resting value.

The cardiac output and stroke volume increase occurring after conversion to sinus rhythm are unaffected by the therapy employed.

\section{Discussion}

Ferrer et al. (1952) and Wade et al. (1952) measured the cardiac output in patients with atrial fibrillation and in patients in sinus rhythm. They found the mean cardiac output to be higher in the latter group. All suffered from rheumatic heart disease and the two groups had a similar degree of clinical disability. They concluded that the cardiac output was reduced in patients with atrial fibrillation. However, similar clinical disability does not necessarily mean similar hæmodynamic disturbance. Patients with atrial fibrillation may be more affected by the disease process than patients in sinus rhythm and thus the difference in cardiac output in the two groups might not be due to the presence or absence of atrial fibrillation alone. Kory and Meneely (1951) and Hecht, Osher, and Samuels (1951) studied 8 and 15 patients respectively, measuring the cardiac output before and after conversion to sinus rhythm by quinidine sulphate. They demonstrated an increase in resting cardiac output in the majority after conversion to sinus rhythm. This increase was more marked when the cardiac output after exercise was studied. Hansen, McClendon, and Kinsman (1952) studied 14 patients. No change was found in 5 and there was an
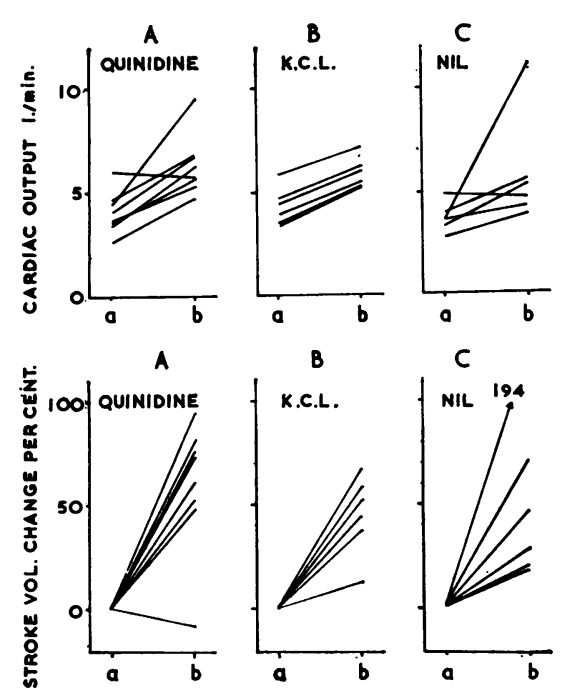

FIG. 4.-The upper panel shows the change in cardiac output before (a) and after (b) conversion of atrial fibrillation to sinus rhythm. The lower panel shows the change in stroke volume expressed as a percentage of the resting figure. (A) Patients given quinidine sulphate. (B) Patients given potassium chloride. (C) Patients not receiving any drug therapy. increase of less than 10 per cent in the remaining 9. Small increases in cardiac output after conversion to sinus rhythm have also been noted by Storstein and Tveten (1955), Broch and Müller (1957), and Gilbert et al. (1963).

These results indicate some increase in cardiac output after conversion from atrial fibrillation to sinus rhythm. Quinidine was used for conversion and for maintaining sinus rhythm. The part played by quinidine in the increased cardiac output is uncertain.

More recently, Graettinger, Carleton, and Muenster (1963) studied 21 patients. With one exception no increase in cardiac output was found though the stroke volume did increase. In a recent appraisal of atrial transport function Burchell (1964) was not impressed by the evidence for a decrease in cardiac output following the onset of atrial fibrillation. He quotes one case of atrial fibrillation developing during cardiac catheterization where no change in oxygen saturation of mixed venous blood occurred in spite of a considerable increase in heart rate.

Our results demonstrate a well-marked rise in the resting cardiac output of patients with atrial fibrillation following conversion to sinus rhythm. The average increase in these 20 patients was 53 per cent. When atrial 
fibrillation reappeared in 3 patients the cardiac output returned towards pre-conversion levels. In 3 patients studied in whom sinus rhythm persisted the cardiac output remained raised. In the 10 patients in whom the attempted conversion failed the average change in cardiac output was $2 \cdot 7$ per cent. The only difference between the treatment of the patients who converted to sinus rhythm and those who did not was that the latter received digitalis.

Table $I$ indicates that the heart rate in the patients with atrial fibrillation who were receiving digitalis therapy was similar to the heart rate after conversion to sinus rhythm. The stroke volume shows a considerable increase after conversion.

The increase in cardiac output was not related to drug therapy given after conversion. We have found that similar increases occur whether patients receive quinidine sulphate, potassium chloride, or no therapy following conversion.

\section{SUMMARY}

The resting cardiac output was estimated in 30 patients with atrial fibrillation before and after attempted direct current conversion. An increase in output and stroke volume was noted in the 20 patients in whom sinus rhythm was established. The mean increase in output was 53 per cent. This increase appears to be independent of drugs. No significant change in the cardiac output was noted in 10 patients in whom direct conversion failed. When, after successful conversion, atrial fibrillation recurred cardiac output fell to pre-conversion levels.

We wish to thank Dr. J. F. Pantridge for helpful criticism and for permission to study these patients who were under his care.

\section{REFERENCES}

Broch, O. J., and Müller, O. (1957). Hæmodynamic studies during auricular fibrillation and after restoration of sinus rhythm. Brit. Heart J., 19, 222.

Bruce, T. A., and Shillingford, J. P. (1962). The normal resting cardiac output: serial determinations by a dye dilution method. Brit. Heart J., 24, 69.

Burchell, H. B. (1964). A clinical appraisal of atrial transport function. Lancet, 1, 775.

Ferrer, M. I., Harvey, R. M., Cathcart, R. T., Cournand, A., and Richards, D. W., Jr. (1952). Hemodynamic studies in rheumatic heart disease. Circulation, 6, 688 .

Gilbert, R., Eich, R. H., Smulyan, H., Keighley, J., and Auchincloss, J. H. (1963). Effect on circulation of conversion of atrial fibrillation to sinus rhythm. Circulation, 27, 1079.

Graettinger, J. S., Carleton, R. A., and Muenster, J. J. (1963). Circulatory consequences of changes in cardiac rhythm produced in patients by transthoracic direct-current shock. (abstract). J. clin. Invest., $42,938$.

Hansen, W. R., McClendon, R. L., and Kinsman, J. M. (1952). Auricular fibrillation: hemodynamic studies before and after conversion with quinidine. Amer. Heart J., 44, 499.

Hecht, H. H., Osher, W. J., and Samuels, A. J. (1951). Cardiovascular adjustments in subjects with organic heart disease before and after conversion of atrial fibrillation to normal sinus rhythm. $J$. clin. Invest., 30, 647.

Kory, R. C., and Meneely, G. R. (1951). Cardiac output in auricular fibrillation with observations on the effects of conversion to sinus rhythm. J. clin. Invest., 30, 653 .

Lown, B., Amarasingham, R., and Neuman, J. (1962). New method for terminating cardiac arrhythmias; use of synchronized capacitor discharge. J. Amer. med. Ass., 182, 548.

Storstein, O., and Tveten, H. (1955). The hemodynamic effect of restoring normal sinus rhythm in patients with auricular fibrillation. Scand. J. clin. Lab. Invest., 7, 167.

Wade, G., Werkö, L., Eliasch, H., Gidlund, A., and Lagerlöf, H. (1952). The hæmodynamic basis of the symptoms and signs in mitral valvular disease. Quart. J. Med., 21, 361. 